\title{
COMPROMISO POLÍTICO Y FEMINISMO EN EL UNIVERSO COMUNISTA DE LA TRANSICIÓN ${ }^{1}$
}

\author{
Mónica Moreno Seco \\ monica.moreno@ua.es \\ Universidad de Alicante
}

Recibido: 28-02-2013

Aceptado: 20-03-2013

\section{Resumen}

En el proceso de Transición a la democracia, las culturas políticas comunistas ocuparon una posición muy destacada, con diversos horizontes, desde la vía democrática al socialismo del PCE a las propuestas revolucionarias maoístas y trotskistas. Las mujeres que militaron en estos partidos, que también participaron en el movimiento feminista, reformularon las identidades de género de la izquierda con debates teóricos muy intensos y nuevas prácticas políticas y sociales. Aunque no alcanzaron sus objetivos políticos y feministas, ni un reconocimiento en las urnas, contribuyeron de forma decisiva a la consolidación de la democracia y la difusión de discursos y valores igualitarios en España.

Palabras clave: mujeres, comunismo, extrema izquierda, feminismo, género, transición a la democracia.

\begin{abstract}
In the transition to democracy, communist political cultures occupied a very prominent position, with different proposals, from the PCE democratic road to socialism to Maoist and Trotskyist revolutionary ones. Women who milited in those parties, who also participated in the feminist movement, reformulated left gender identities with very intense theoretical debates and new political and social practices. Although they had not achieved their political and feminist objectives, or the recognition in the ballot boxes, they have made a decisive contribution to the consolidation of democracy and the spread of egalitarian discourses and values in Spain.
\end{abstract}

Key words: women, communism, extreme left, feminism, gender, transition to democracy.

\footnotetext{
${ }^{1}$ Este estudio ha sido realizado en el marco del Proyecto de investigación "Haciendo Historia. Género y Transición en España" financiado por el Ministerio de Ciencia e Innovación (ref. FEM2010-19068).
} 


\section{Introducción}

En la movilización social que impulsó a numerosas mujeres y hombres a militar contra la dictadura franquista y por una sociedad más justa y libre durante la Transición a la democracia, se difuminaron las fronteras entre acción sindical, ciudadana, feminista o política en sentido estricto. En las trayectorias de muchas personas que participaron en el antifranquismo, el paso de una militancia a otra o de asociaciones a partidos fue frecuente, lo cual redundó en el fortalecimiento de una sociedad civil que se impregnó de valores democráticos (Pérez Ledesma, 2006: 122-123). La difusión de culturas políticas de izquierda, con lenguajes de democracia o revolución, y la diversidad de experiencias vitales en el trabajo, los centros de estudio o los barrios, condujeron a una creciente implicación en iniciativas y acciones que intentaron derrocar el régimen franquista. Para muchas mujeres, la crítica a la dictadura y el diseño de la futura sociedad española estaban íntimamente ligados a unas relaciones de género igualitarias y respetuosas con la diferencia.

El compromiso social y político adquirió nuevas dimensiones cuando el movimiento feminista, en auge en esos años, logró introducir en la agenda política aspectos vinculados a los discursos igualitarios y reivindicaciones que hasta ese momento se consideraban propios del ámbito privado, como los derechos reproductivos (Nash, 2009). Con debates teóricos muy intensos, en torno a la militancia de las mujeres y las relaciones entre política y feminismo, en las culturas políticas progresistas se cuestionaron las formas de hacer política, con el objetivo de consolidar un régimen democrático en España o de plantear una revolución. Con límites, se consiguió que los valores, los símbolos y lenguajes feministas impregnaran las culturas políticas de izquierda.

En concreto, en este texto se analizan las propuestas políticas y feministas de las culturas políticas comunistas, desde el abierto apoyo a la democracia del PCE -la "vía democrática al socialismo"- a los proyectos revolucionarios maoístas y trotskistas, que fueron evolucionando de diversa manera a medida que el proceso de cambio político se fue institucionalizando. Nos interesa, pues, poner de relieve cómo en estas culturas políticas se fueron gestando discursos, representaciones y experiencias que contribuyeron a la conformación de determinadas identidades de género, que buscaron una redefinición de la masculinidad y la feminidad en el universo comunista, recogiendo los planteamientos teóricos propuestos por Aguado y Ortega (2011: 11-19). Y a la vez cómo las identidades comunistas estaban matizadas por la pertenencia de sus militantes a diferentes colectivos sociales o por la diversidad de trayectorias vitales (Domènech Sampere, 2010: 105), en especial para el caso que nos ocupa cómo mujeres y hombres se sentían comunistas.

Aun partiendo de la misma matriz ideológica, el marxismo-leninismo, y de un planteamiento común en defensa del denominado feminismo socialista y de la doble militancia, vamos a introducirnos en las diferencias entre el feminismo reformista y la opción democrática del PCE por un lado, y las posturas revolucionarias, tanto feministas como políticas, de la 
extrema izquierda por otro. Ninguna de las dos opciones, que habían sido protagonistas en el desgaste del franquismo, sobre todo el PCE, pero en cierta medida también la izquierda revolucionaria, consiguió espacios destacados de representación en la naciente democracia.

Sin embargo, las mujeres que militaban en ellos fueron activistas fundamentales en el movimiento feminista, que obtuvo logros muy importantes, aunque no consiguiera un reconocimiento amplio por parte del mundo político, de la sociedad y de los medios de comunicación (Nash, 2011 y Radcliff, 2009). A diferencia del PSOE, quien no desarrolló un interés abierto por el feminismo hasta ya consolidados los cambios democráticos, las militantes comunistas (ortodoxas o revolucionarias) fueron sustento muy importante, aunque no exclusivo, del movimiento de mujeres: las integrantes del PCE sobre todo en sus orígenes, y las de la extrema izquierda, con sus matices y diferencias, en su momento de auge entre 1975 y 1979, e incluso hasta principios de los ochenta. Más allá de su participación en ámbitos de poder, sin ellas la democracia habría sido menos igualitaria y participativa, como se ha señalado para el feminismo en términos generales (Verdugo Martí, 2011).

\section{En el PCE: democracia, socialismo y liberación de las mujeres}

Las relaciones entre el PCE y la democracia han de abordar tanto la contribución del partido comunista en la implantación de un sistema democrático en España como la incorporación por parte de esta formación de la democracia como un valor fundamental en la estrategia de transición al socialismo (Sánchez Jiménez, 2004). El distanciamiento respecto a la doctrina emanada de la URSS y la influencia de la lucha contra la dictadura marcaron el rumbo interno del PCE desde mediados de los años cincuenta, en el que la democracia pasó a ocupar un lugar central. Por otro lado, este giro supuso un cambio de estrategia que condujo a focalizar el interés político en la movilización social, contribuyendo a difundir valores democráticos y progresistas para consolidar la sociedad civil y acabar con la dictadura. Esta opción política influyó de forma poderosa en el desarrollo de movimientos sociales -obrero, estudiantil, vecinal o feminista-, así como en la "acumulación de fuerzas" que hizo imposible la continuidad de la dictadura (Molinero, 2010).

Los nuevos planteamientos abrieron espacios que permitieron la incorporación de muchas mujeres no politizadas al activismo social, en la solidaridad con los presos, asociaciones de barrios o de amas de casa, para implicarse progresivamente en la oposición política, tarea en la que destacó la acción de las militantes con formación y conciencia política previas (Abad Buil, 2012). Si el objetivo en una primera época fue ampliar los focos de antifranquismo con movilizaciones contra la carestía de la vida o por unas condiciones dignas de habitabilidad en los suburbios, es decir, con acciones que se ajustaban a planteamientos de género que reducían a las mujeres a esposas y amas de casa, de forma paulatina se fueron introduciendo nuevas preocupaciones con el intercambio de experiencias y la actividad común 
en estas organizaciones, y con la afiliación de jóvenes, trabajadoras y estudiantes, más autónomas y formadas (Erice Sebares, 1996: 334). En el interés por la acción política directa y el feminismo fueron cruciales las insatisfacciones y cuestionamientos de muchas mujeres del partido. Las diferencias residían en buena cuenta en la concepción de la militancia y del partido, es decir, en diferentes interpretaciones sobre la identidad de las mujeres comunistas, entre la fidelidad completa al partido de las más veteranas a una posición más crítica de las más jóvenes o universitarias.

En este sentido, la cultura comunista tradicional, que contemplaba entre otros aspectos unas relaciones de género desiguales, entró en crisis en los años setenta, con la mezcla de generaciones, diferentes extracciones sociales y por el contacto con los movimientos sociales (Erice Sebares, 2010: 178). Un proceso, sin embargo, que no ha sido estudiando a fondo en sus implicaciones de género. En este sentido, cabe destacar que en la Transición las afiliadas del PCE no obedecían a un patrón único, sino que existía una notable pluralidad de formas de vivir el compromiso político: militantes de más edad que habían experimentado la clandestinidad y la represión en los peores momentos de la dictadura, para quienes el partido era una fuente incontestable de orientación doctrinal y ética, jóvenes que habían sido socializadas por familias de tradición comunista, otras que descubrieron el comunismo por el contacto con compañeros de universidad o trabajo, estudiantes que hicieron una interpretación de los valores y principios comunistas desde el tamiz de lecturas diversas, obreras que participan en la movilización sindical, otras para quienes las contradicciones de sus camaradas y maridos les llevan a buscar referentes feministas, jóvenes sin responsabilidades familiares que se entregan de lleno al compromiso, madres que intentaban hacer compatible la acción política con la atención a sus hijos, etc. En una encuesta realizada por Mundo Obrero (10-04-1977: 8) a militantes de base tras la legalización del partido, algunas mujeres -en especial las jóvenes- indicaron que estaban en el partido por razones políticas; otras, de mediana o avanzada edad, aludían a sus familiares varones ("Mi marido y mi hijo han pasado cuarenta años en la Unión Soviética. Yo estoy en el Partido porque mi padre me enseñó la doctrina desde que nací”) y otras denotaban su convencimiento pero sin dejar de mencionar su pertenencia a una genealogía comunista: "soy hija de un comunista fusilado [...]. Estoy porque creo que es el único [partido] que mira de verdad por el obrero". De hecho, Dolores Ibárruri, referente moral y mítico que representaba esa cultura comunista tradicional marcada por el recuerdo de la Guerra Civil y el sacrificio, proporcionaba un anclaje simbólico con una acción política de larga tradición, pero no se ajustaba ya a las inquietudes ni al lenguaje de muchas militantes (Cruz, 1999: 231-242).

La acción feminista de las camaradas del PCE supuso una doble militancia, dentro del partido y en el movimiento feminista, enriquecedora pero no exenta de tensiones. Como integrantes de una formación política con larga trayectoria, su evolución fue muy destacada, al partir de la teoría marxista clásica sobre la opresión de las mujeres (Engels, Bebel), que subordinaba toda acción reivindicativa a la revolución socialista, para acabar elaborando discursos igualitarios pero también identitarios de claro contenido feminista (tomo la idea de Aguado, 2010), que obligaron al partido a reformular muchas de sus posiciones de origen. 
Primero consiguieron que se admitieran las limitaciones del marxismo clásico y que los problemas de las mujeres no se circunscribían a las obreras, después que se entendiera que sin la liberación de las mujeres el socialismo no sería completo. En el IX Congreso se aprobó la tesis de que para acabar con la discriminación de las mujeres había que acabar con el capitalismo, pero también que el socialismo no sería tal sino desaparecía la discriminación de clase y de sexo (Nuestra Bandera, mayo-junio de 1978: 74-76). Y, de forma paralela, defendieron que la incorporación de mujeres al partido y a la defensa de la democracia debía acompañarse de un replanteamiento de las relaciones entre mujeres y hombres dentro de la organización, que condujera a valorar su militancia en el feminismo y en otros movimientos sociales, garantizar su acceso a puestos de responsabilidad e, incluso, remover los prejuicios de guiaban las actitudes y comportamientos de muchas y muchos afiliados (Moreno Seco, en prensa a).

Los discursos igualitarios y la denuncia de la discriminación laboral y social de las mujeres ya estaba presente en militantes y simpatizantes del partido a principios de los años sesenta, que escribieron cartas a la redacción de Radio España Independiente ("la Pirenaica") expresando estas inquietudes ${ }^{2}$. En la década siguiente, con una labor cotidiana y no siempre bien entendida, militantes y dirigentes como $\mathrm{M}^{\mathrm{a}}$ Dolores Calvet, Begoña San José o Rosalía Sender hicieron oír sus voces en distintos órganos del partido, debatieron sobre feminismo y marxismo en la prensa vinculada al mismo, como Mundo Obrero o Nuestra Bandera, y convocaron foros de discusión sobre la situación de las mujeres (Sender Begué, 2006).

La Comisión del Comité Central para la Cuestión Femenina se creó en 1976, con Dulcinea Bellido, Rosalía Sender, Mercedes Comabella, Tina Guillén, Manuel Azcárate y Jaime Ballesteros, y desde muy pronto asumió las demandas del feminismo del momento: amnistía para las mujeres condenadas por motivos políticos o por adulterio y practicar abortos, trabajo en igualdad de condiciones, derecho a una educación no discriminatoria, despenalización de los anticonceptivos, matrimonio civil o eliminación del servicio social vinculado a la Sección Femenina ${ }^{3}$. La comisión convocó ese mismo año la Primera Conferencia para la Liberación de la Mujer del PCE, que partió del presupuesto teórico que plateaba la lucha feminista y por la democracia y el socialismo como paralelas, y admitió la necesidad de un movimiento feminista autónomo, defendiendo la doble militancia (PCE, 1976 y Mundo Obrero, 24-11-1976: 8). En la siguiente Conferencia, celebrada en diciembre de 1978, se reconoció la pluralidad del movimiento feminista y en consecuencia que la actuación de las comunistas fuera libremente escogida, una experiencia que se creía podía enriquecer la teoría y la praxis política del partido (Nuestra Bandera, enero de 1979: 33).

La presión de las militantes, junto con el deseo de integrar a las mujeres en la movilización antifranquista y el auge del feminismo influyeron en la incorporación de las tesis feministas al discurso oficial del PCE. Para ello, se tuvo que superar la concepción del feminismo como un movimiento burgués que planteaba reivindicaciones ajenas a las mujeres

\footnotetext{
${ }^{2}$ Archivo Histórico del PCE, Sección Radio España Independiente, carps. 175/12 o 188/11, entre otras.

${ }^{3}$ Archivo Histórico del PCE, Sección Organizaciones de Mujeres, caja 117, carp. 12.
} 
de clase obrera, colectivo que encarnaba la identidad femenina comunista. En Viento del Pueblo (1975: 5), revista del partido en Alicante, se afirmaba en julio de 1975 que las mujeres de extracción popular que trabajan fuera de casa no debían abandonar la labor en el hogar, "tarea indispensable para la reconstitución de la fuerza de trabajo del marido obrero", y que la cuestión feminista es para los movimientos burgueses una finalidad en sí misma, mientras que "para las mujeres de clase obrera no debe ser sino un paso más hacia la constitución de una sociedad sin clases".

En la II Conferencia Nacional del Partido, que tuvo lugar en 1975, el PCE se definió como "el partido de la liberación de la mujer": "El Partido Comunista destaca el mérito de los movimientos feministas. Coincidimos con su objetivo: lograr la igualdad de la mujer y del hombre. En este sentido somos, debemos ser, un Partido feminista. Somos el Partido de la Liberación de la Mujer" (Mundo Obrero, $3^{\mathrm{a}}$ semana de octubre de 1975: VII). No obstante, advirtió que el error del feminismo radical constituía en considerar exclusivo el "problema femenino", pues no podía resolverse al margen de las transformaciones políticas y sociales. En esta Conferencia se defendieron reivindicaciones feministas como la despenalización de los anticonceptivos o el divorcio, y se hizo autocrítica: "somos conscientes de que en nuestras propias filas la discriminación de la mujer es una realidad; y de que aún muchos comunistas tienen ideas reaccionarias sobre el problema femenino", por lo cual se consideraba urgente emprender una "revolución de las mentalidades" para acabar con los prejuicios anclados en la mente de la mayoría (Mundo Obrero, $4^{\mathrm{a}}$ semana de septiembre de 1975: 8). Esta orientación se consolidó en el IX Congreso del Partido, en abril de 1978, en que se insistió en que la lucha feminista era una tarea fundamental del partido, que formaba parte de la lucha común de quienes aspiraban a transformar la sociedad (Nuestra Bandera, nº 93, mayo-junio de 1978: 7475).

Voces feministas dentro del partido, como la de Sara Iribarren, reclamaban que se ofreciera a las militantes y las mujeres que querían ingresar en la formación "un espacio liberador, igualitario, donde pueden liberar su potencial humano y revolucionario, y actuar como seres independientes y responsables, desarrollar su capacidad de pensar y de crear y, en definitiva, romper sus cadenas" (Iribarren, 1975: VI). Estas palabras remiten a un claro replanteamiento de las identidades de género en el PCE. En este sentido, el código moral del partido desarrollado en la cultura comunista tradicional, que juzgaba de forma diferente a mujeres y hombres, dio lugar a tensiones abiertas en los años setenta. La llegada creciente de mujeres al partido y la incorporación de reivindicaciones feministas introdujeron fracturas en las relaciones tradicionales de género, incluso con trasgresiones en las expresiones de afectividad y sexualidad que cuestionaron el rigorismo moral comunista anterior (Domènech Sampere, 2010: 126-132). Una destacada comunista, Natalia Calamai, reclamaba en Nuestra Bandera (Calamai, 1977: 44):

"La liberación de la mujer se conseguirá sólo cuando se consiga oponer a la moral burguesa una moral nueva, en una sociedad en que haya desaparecido la explotación del hombre por el hombre y en que se inicie el complejo proceso de construcción de un ser humano auténticamente libre. 
Por ello es fundamental enmarcar la lucha feminista dentro de la lucha contra el tipo de sociedad concreta en que se produce la opresión de la mujer".

Ese cambio moral suponía, a su juicio, la distinción entre sexualidad y procreación, y un replanteamiento de la institución familiar para que la incorporación al trabajo fuera realmente un elemento emancipador.

Cuando se daba la militancia de los dos cónyuges, lo cual era bastante frecuente, las responsabilidades familiares y domésticas habían recaído hasta ese momento en las mujeres, que veían cómo su compromiso político decaía o se hacía muy difícil ante la falta de tiempo y reconocimiento (Sender Begué, 2004); en los setenta, al menos en las parejas jóvenes, las relaciones eran más igualitarias y las redes familiares ayudaban a afrontar las obligaciones que imponía el compromiso político (Díaz, Alcaraz, 13-06-2006; Reig Cruañes, 13-06-2006; Sanjuán Ayelo, 01-02-2013). Las tensiones se planteaban entre camaradas, varones y mujeres, pero también entre veteranas y jóvenes, en torno a la prioridad que había que conceder a las demandas feministas en la movilización antifranquista $\mathrm{y}$, con frecuencia, en el fondo, en torno a cuestiones morales, pues las reivindicaciones referidas al cuerpo y la sexualidad eran consideradas burguesas y frívolas en muchos casos.

No obstante, las propuestas más trasgresoras fueron incorporándose al discurso oficial del partido. En el IX Congreso, de 1978, se afirmó: "es inalienable el derecho de la persona a la elección sexual no mediatizada por exigencias represivas de la legislación actual, y a una afectividad libremente elegida" (Nuestra Bandera, mayo-junio de 1978: 76). En la II Conferencia de la Liberación de la Mujer, Pilar Pérez Fuentes propuso replantear los viejos modos de hacer política para introducir nuevos valores vinculados a lo privado (familia, sexualidad, relaciones personales) y propuso una forma de militancia que no reprodujera el modelo masculino (Nuestra Bandera, enero de 1979: 35-36). En el X Congreso, por último, se defendió la tesis de que el PCE debía oponerse al modelo de familia patriarcal (Mundo Obrero, 16 a 22-11-1981: 14-15).

Este cuestionamiento profundo de los discursos de género que hasta entonces habían estado vigentes en el partido no significó que se eliminaran todos los obstáculos a la militancia de las mujeres y su acceso a puestos de responsabilidad; las autocríticas en este sentido continuaron siendo recurrentes en la oratoria oficial. Por otro lado, las disparidades entre las resoluciones oficiales y las convicciones de la militancia de base eran frecuentes. En el IX Congreso del PCE, mientras el documento aprobado subrayaba la importancia del movimiento feminista y consideraba fundamental que el partido "comprenda y fomente estos movimientos de mujeres, respetando totalmente la independencia ideológica y política de éstos, y que colabore con ellos", la delegación de Asturias había planteado que el PCE no apoyara a movimientos feministas por entenderlos como movimientos de enfrentamiento entre los dos sexos (Mundo Obrero, 20-04-1978: 6 y Nuestra Bandera, mayo-junio de 1978: 75) . 
No obstante, es cierto que el acceso, aunque fuera limitado, al parlamento y la administración local permitió a las comunistas apoyar reivindicaciones del movimiento de mujeres desde dichas instancias. Las diputadas, en especial $\mathrm{M}^{\mathrm{a}}$ Dolors Calvet, defendieron enmiendas a la Constitución, que creían que eran un marco adecuado para afianzar el avance de los derechos de las mujeres aun reconociendo sus defectos y límites, y presentaron proposiciones de ley en demanda de la amnistía por los delitos "femeninos", el divorcio y la despenalización del aborto (Mundo Obrero: 03-08-1977: 4; 18 al 24-06-1978: 4; 22 a 28-05-1980: 22-23 y Calamai, 1978: 15). Además, las integrantes del PCE decidieron colaborar con los organismos oficiales que se ocupaban de la situación de las mujeres, como la Subdirección de la Comisión Femenina creada por el gobierno de la UCD, o el Instituto de la Mujer, aunque fue una decisión que provocó el enfrentamiento entre quienes pensaban que reconduciría al movimiento de mujeres hacia planteamientos reformistas y aquellas que eran partidarias de dialogar con la administración (Calamai 1978a: 14 y Pardo Buendía, 1978: 14).

En el movimiento feminista su presencia se articuló sobre todo por medio del Movimiento Democrático de Mujeres ${ }^{4}$. El MDM surgió en 1965, abierto a mujeres de distintas procedencias pero impulsado por militantes del PCE interesadas en la lucha política, la atención a los presos políticos y la acción en los barrios (Abad Buil, 2005). Con la incorporación de mujeres jóvenes, que leían no solo a los teóricos marxistas sino también a Simone de Beauvoir y otras autoras feministas, el MDM se convirtió en MDMMLM (Movimiento de Liberación de las Mujeres) en 1975, con una marcada orientación reivindicativa, al reclamar la acción feminista como elemento esencial de la movilización por la democracia y por el socialismo, o al priorizar reivindicaciones como el divorcio o el aborto (Mundo Obrero, 29-09-1976: 9-11).

A partir de la legalización del partido en 1977 se planteó una paradoja, pues mientras muchas tesis feministas se integraron en el discurso oficial de la formación, el trabajo interno en el partido absorbió las energías de muchas comunistas feministas y su actividad en movimientos sociales muchas veces tuvo que pasar a un segundo plano. Los programas electorales de 1977 y 1979, a pesar de todo el trabajo interno que se había realizado y de la propia actuación de las parlamentarias de un partido que se autodenominaba feminista, no recogieron demandas básicas como el divorcio o el aborto, una equivocación según Amparo Rubial, candidata por Sevilla en 1979, que en su opinión obedecía a razones de cálculo electoral pero no reflejaba los principios asumidos por el partido (Rubial, 1979: 4). Tampoco las listas electorales incorporaron un número destacado de candidatas. Esta institucionalización de la política del PCE y las derrotas electorales supusieron un duro golpe para las esperanzas de alcanzar una democracia en profundidad que condujera al socialismo y la igualdad plena.

\footnotetext{
${ }^{4}$ Archivo Histórico del PCE, Sección Organizaciones de Mujeres, carps. 2 y 13.
} 


\section{En la extrema izquierda: feminismo y revolución}

Coincidiendo con la ola de rebeldía juvenil que se extendió por occidente, la izquierda revolucionaria surgió en España a principios de los años setenta y participó de forma destacada en el desgaste del franquismo. Las formaciones que tuvieron mayor desarrollo fueron el PTE (Partido del Trabajo de España), la ORT (Organización Revolucionaria de Trabajadores), el MC (Movimiento Comunista) y la LCR (Liga Comunista Revolucionaria). Las tres primeras estuvieron vinculadas al maoísmo, mientras la última se adscribió al trotskismo, de manera que representaban propuestas ideológicas insertas en la tradición marxista y en el universo comunista (Laiz, 1995). En estas culturas políticas comunistas heterodoxas, que buscaban referentes también en los procesos de descolonización y cambio político del Tercer Mundo, la movilización contra la dictadura estaba impregnada de imaginarios y discursos revolucionarios (Roca, 1993).

Su radical cuestionamiento de las estructuras políticas, sociales y familiares permitió que incorporaran con relativa facilidad las propuestas feministas que fueron introduciendo las militantes, quienes vinculaban revolución a liberación de las mujeres (Moreno Seco, en prensa b). No solo aceptaban abiertamente el divorcio o el aborto, sino que cuestionaron desde muy pronto la familia patriarcal y la heterosexualidad obligatoria. Por ello, criticaron con severidad al PCE y en general a lo que denominaban izquierda reformista, a quien acusaban de sacrificar los planteamientos más avanzados del feminismo en aras del consenso político -por ejemplo, en el debate constitucional- y de renunciar a un cambio profundo de la sociedad.

$\mathrm{Al}$ igual que las integrantes del PCE, las afiliadas de la extrema izquierda desarrollaron una doble militancia en sus partidos y en el movimiento feminista, en un contexto en que el alto grado de activismo de la militancia condujo a una presencia importante en el antifranquismo. En primer lugar, plantearon un intenso cuestionamiento de las bases teóricas y la estrategia de sus formaciones políticas, intentando conjugar el marxismo y la liberación de la mujer, pues estaban convencidas de la validez de las tesis marxistas para transformar la sociedad pero también advertían las limitaciones de ese marco teórico, que negaba la especificidad de las reivindicaciones de las mujeres (Uría Ríos, 2009: 17-33). Cuestionaban el trabajo reproductivo ejercido por las mujeres en el hogar y la familia como medio de transmisión de la propiedad y de mantenimiento de las clases sociales, que servía al capitalismo para reproducir su ideología y amortiguar los problemas sociales, según se aprobó en el II Congreso del MC (1978). Estas formaciones admitieron públicamente que "los y las comunistas asumimos sin reservas la causa de la liberación de la mujer, doblemente oprimida por el capitalismo y por la dominación masculina" (MC-OIC, 1978). Como puede comprobarse, desarrollaron las tesis del feminismo socialista desde un lenguaje revolucionario muy imbuido de la crítica feminista.

En consecuencia, consideraban la movilización feminista como un elemento clave en la acción revolucionaria. Además, intentaron transformar las prácticas políticas internas de sus partidos y elementos simbólicos clave de su identidad, reclamando el acceso de las mujeres a 
los puestos de responsabilidad orgánicas y que sus propuestas fueran debatidas y asumidas por los partidos y toda la militancia. Cabe tener en cuenta que su presencia numérica era destacada: en 1976, la LCR contaba con un $32 \%$ de mujeres entre sus militantes (Combate, $1^{\text {a }}$ quincena de septiembre de 1976: 10), un porcentaje bastante similar al del MC (Ruiz y Romero: 1977: 59). Algunas alcanzaron cotas de poder, como Pina López Gay, que fue elegida secretaria general de la Joven Guardia Roja (PTE), y Lola Albiac, responsable de la Federación de Juventudes Revolucionarias (MC), o formaron parte de los comités centrales de sus partidos, aunque sin alcanzar una representación proporcional a su militancia. En las candidaturas electorales, tuvieron una presencia destacada, superior a la de otros partidos de izquierda como el PCE o el PSOE (Yzaguirre, 1979: 21).

Dando un paso más, cuestionaron las actitudes cotidianas de sus compañeros de militancia, reclamando en ocasiones que la manera de relacionarse con las camaradas y con sus parejas fuera un criterio a tener en cuenta en la elección de cargos internos. Cabe recordar que el compromiso de los afiliados y afiliadas, en su mayoría jóvenes provenientes de las fábricas y las universidades, suponía una severa moral revolucionaria que les condujo en ocasiones a abandonar sus familias, dejar los estudios y optar por una vida proletaria, pero también asumir formas de comportamiento y una sexualidad trasgresoras. Como señalaba en un documento interno la Jove Germania, agrupación juvenil del MC en el País Valenciano, para un comunista la búsqueda de la satisfacción personal estaba subordinada a lucha, pero debía existir la libertad de los y las militantes en las satisfacciones personales ${ }^{5}$. La entrega revolucionaria reclamó muchos sacrificios personales pero también impulsó con frecuencia la adopción de maneras de vivir libremente elegidas; aunque se dio el caso de homosexuales que aceptaron el matrimonio para intentar corregir su opción sexual como elemento burgués que había que superar (Rodríguez Tejada, 2011: 647), las feministas consiguieron que las resoluciones oficiales de sus formaciones incluyeran la homosexualidad como opción afectiva, el libre control del cuerpo por parte de las mujeres o la concepción de la sexualidad como una relación libre entre personas libres (MC, 1978). Para muchas mujeres de la extrema izquierda, el compromiso condujo a contravenir las pautas convencionales de la acción política y la moral (Moreno Seco, en prensa b).

En algunos casos crearon organismos de mujeres en sus partidos, como la Estructura Autónoma de Mujeres del MC (Servir al Pueblo, 2a quincena de abril de 1978: 19) o la Comisión de Trabajo Mujer de la LCR, elaboraron abundante material de discusión teórica, opinaron en los periódicos y revistas orgánicos, y convocaron jornadas del partido para debatir las tesis feministas. La Primera Conferencia sobre la Mujer de la LCR (n.d. a) reclamó la erradicación de las actitudes discriminatorias en el partido y que el debate sobre la opresión de las mujeres obtuviera reconocimiento político. Fruto de este esfuerzo, a diferencia del PCE, en los programas electorales de la extrema izquierda se incluyeron de manera abierta demandas como la despenalización del aborto, el derecho al placer y al control del propio cuerpo o el derecho al libre desarrollo de la sexualidad.

\footnotetext{
${ }^{5}$ Arxiu de la Memòria-Archivo Municipal de Elche, Documents, Caja 2-D.
} 
No obstante, el trabajo feminista en sus partidos, más allá de los discursos oficiales, se encontró con resistencias entre algunos militantes varones (Sauquillo, 16-11-2012). Muchos se aferraban a la tesis clásica de que el feminismo era una propuesta burguesa y que el interés del "feminismo obrero" debía circunscribirse a unas mejores condiciones laborales y de habitabilidad de las trabajadoras (Escudero Andújar y González Martínez, 2011: 528-529). En otros casos no se trataba tanto de un rechazo abierto sino de falta de consideración de las demandas de las mujeres, como se denunciaba en ocasiones, circunstancia que revela la pervivencia de actitudes y sentimientos tradicionales y los límites al replanteamiento de las identidades de género. Sin embargo, como se trataba de formaciones políticas de reciente creación y de composición bastante homogénea, no hubo tensiones destacadas entre mujeres, pues en su gran mayoría pertenecían a una generación urbana, identificada con la contracultura juvenil que rechazaba el autoritarismo en todo tipo de estructuras, desde la económica o la política a la moral y familiar.

Por otro lado, también militaron en el feminismo, impulsando organizaciones como la ADM (Asociación Democrática de la Mujer, vinculada al PTE) o la ULM (Unión para la Liberación de la Mujer, auspiciada por la ORT), o participando en plataformas y coordinadoras comunes, como hicieron las mujeres de la LCR y el MC. Su presencia en el movimiento feminista constituyó una aportación teórica y organizativa fundamental, y si bien en un primer momento se planteó como una forma dotar de contenido revolucionario al feminismo ${ }^{6}$, las influencias mutuas fueron patentes, como se ha visto. Aunque en los últimos años de la dictadura estos partidos recurrieron a estrategias de clandestinidad rigurosas, frente a la salida pública que preconizaba el PCE (Rodríguez Tejada, 2011: 646), ya en la segunda mitad de los setenta y principios de la década siguiente las militantes interesadas por el feminismo se integraron de lleno en el movimiento de mujeres, como parte de un proceso de general de creciente interés en abrirse a los movimientos sociales (Cucó i Giner, 2008: 85-87).

Los partidos de extrema izquierda no obtuvieron respaldo en las elecciones de 1977 en las que todavía no habían sido legalizados, por lo que tuvieron que concurrir a los comicios bajo otras siglas- ni en 1979, hecho que les situó en una posición extraparlamentaria y con una limitada presencia en los ayuntamientos. A partir de este momento, las posiciones ante la política y el feminismo fueron evolucionando de manera diferente: mientras el PTE y la ORT pronto abandonaron los discursos revolucionarios para intentar obtener un espacio político, con la aceptación de la Constitución y de organismos como la Subdirección de la Comisión Femenina, el MC y la LCR se reafirmaron en sus tesis revolucionarias, con un distanciamiento abierto de las Cortes y su labor legislativa, y del feminismo institucional. Si los dos primeros partidos desaparecieron en 1980, tras una fusión que no consiguió frenar su crisis, los dos segundos se volcaron de forma progresiva en el trabajo con los movimientos sociales, por ejemplo en la Comisión pro Derecho al Aborto de Madrid, donde coincidieron Empar Pineda

\footnotetext{
${ }^{6}$ Archivo de la Democracia-Universidad de Alicante, subfondo Inmaculada Fernández Arrillaga, Secretaría Regional Feminista de Madrid del PTE, "Criterios generales de la política feminista del Partido", 10-05-1979.
} 
(MC), Llum Quiñonero (MC) y Justa Montero (LCR), entre otras. La creación del Instituto de la Mujer en 1983 no encontró eco en estas veteranas feministas (fue criticado, por ejemplo, en Servir al Pueblo) (Pineda, 1984: 15).

No obstante, aunque no alcanzaron escaños y muchas veces rechazaron colaborar con entidades oficiales, se implicaron en el cambio legislativo, reclamando una Constitución que garantizara la igualdad y recogiera las reivindicaciones feministas en los términos en los que eran planteados por el movimiento de mujeres (LCR, 1978). También elaboraron proyectos de ley sobre el divorcio o el aborto, reivindicando su condición de derechos básicos y gratuitos (MCPVOEC, 1979 y LCR, n.d. b), en una práctica política que, como se ha señalado, no difería tanto de la emprendida por la izquierda reformista a la que tanto criticaban (Molinero e Ysàs, 2008).

\section{Más allá de las diferencias, un horizonte socialista y feminista}

A pesar de todas las divergencias de planteamiento teórico y estratégico y de muchos enfrentamientos, las comunistas (del PCE, maoístas y trotskistas) coincidían con mujeres de otras procedencias ideológicas en las movilizaciones feministas, en protestas, manifestaciones y conmemoraciones del 8 de marzo en torno a las principales campañas del momento, como el divorcio o el aborto, incluso hasta avanzados los años ochenta. El descontento ante el, a su juicio, limitado alcance de las medidas legislativas impulsadas por los gobiernos de la UCD o incluso del PSOE coincidía en muchos aspectos, aunque lógicamente se formulaba con tonalidades diversas. Ya en proceso de crisis, en 1981, el X Congreso del PCE reprochó al gobierno de la UCD que no hubiera permitido desarrollar la Constitución en sentido progresista, pero reconoció que la izquierda no había conseguido articular la lucha institucional e ideológica con los planteamientos del movimiento feminista, todo lo cual explicaba en parte -se decía- la frustración de las mujeres más conscientes y su alejamiento de las instituciones democráticas (Mundo Obrero, 16 a 22-10-1981: 14-15). Desde la extrema izquierda, se acusaba al PCE de haber cedido ante la presión de las fuerzas más conservadoras ${ }^{7}$.

Si mostraron una clara distancia ante la Iglesia o los partidos de derecha, tanto las afiliadas al PCE como a la izquierda revolucionaria recibieron por igual las críticas del feminismo radical, que sostenía posturas muy reacias a unas prácticas políticas impregnadas de valores patriarcales y en general al poder, que entendía como masculino y excluyente, para defender la militancia única (Nash, 2011: 294 y Augustín Puerta, 2003: 337-340). Las feministas radicales consideraban a las comunistas correa de transmisión de las consignas de sus partidos en el seno del movimiento de mujeres y les recordaban las contradicciones de sus formaciones, que decían defender la igualdad pero no la aplicaban en su funcionamiento interno. Así, comenta Justa Montero (n.d.):

\footnotetext{
${ }^{7}$ Biblioteca del Pavelló de la República de la Universitat de Barcelona, Fondo DPP (MC), caja 2, carp. $1 \mathrm{~A}$.
} 
"te cuestionaba mucho y cuestionaba tu militancia en un partido que no consideraba prioritario lo de mujeres y cuestionaba que la teoría marxista no era capaz de entender en profundidad los mecanismos de opresión y que no había una teoría acabada y que ibas al partido y resulta que esto puede ser un partido con una posición más abierta en este terreno, con una posición más clara, y sin embargo hay muchas resistencias".

Compartían, con distintos alcances, las ideas del feminismo socialista, que no concebía la futura sociedad socialista sin el fin de la discriminación de las mujeres, en una lucha paralela e igualmente importante. En buena cuenta participaban de un mismo lenguaje que conjugaba marxismo y feminismo en torno a conceptos como las mujeres como sujetos revolucionarios, la igualdad formal y real -que solo era posible, se creía, en el socialismo-, la liberación de las mujeres frente al patriarcado y al capitalismo o el feminismo como movimiento autónomo y con potencial revolucionario (Moreno Seco, 2008). Como hemos visto, reformularon principios ideológicos e identitarios básicos en sus partidos, pero frente a otros sectores del movimiento feminista insistían en que la liberación de las mujeres no podía darse en abstracto, sino formando parte de una transformación radical de la sociedad. Justa Montero (n.d.) resume estos planteamientos: "realmente pensábamos que las cosas se tenían que dar de otra forma e íbamos a por todo y en ese ir a por todo, teníamos que elaborar no solo una demanda concreta sino qué tipo de sociedad queríamos”. En las II Jornadas de la Liberación de la Mujer de Granada, en 1979, donde cobró gran importancia la controversia entre partidarias de la doble o la única militancia, $\mathbf{M}^{\mathrm{a}}$ Dolors Calvet subrayó que el feminismo debía reclamar con más fuerza cambios legales y una mayor implicación de la administración local en políticas que mejoraran la situación de las mujeres, negando las acusaciones de manipulación del movimiento feminista (Calvet, 1979: 20-22).

Por otro lado, las trayectorias vitales de muchas afiliadas al PCE o a formaciones de la extrema izquierda son bastante paralelas, a pesar de la mayor heterogeneidad de las primeras: desde el activismo social estudiantil u obrero dieron el paso al ingreso en el partido, y normalmente después descubrieron el feminismo, que con frecuencia les hizo replantearse su militancia y opciones personales. Vivieron experiencias comunes fundamentales y muchas dificultades: la represión (detenciones y cárcel), la violencia de la ultraderecha, la triple jornada (laboral, militante, personal), los problemas para conciliar la doble militancia, la incomprensión de sus compañeros de partido, el sacrificio de muchos proyectos personales y de las relaciones familiares. Pero también establecieron lazos y participaron de las mismas movilizaciones, y compartieron entusiasmo y confianza en un futuro más libre, justo e igualitario. La valoración que suelen hacer de su trabajo feminista y de la colaboración con mujeres de diferentes procedencias ideológicas es muy positiva, aun reconociendo que no se logró todo lo que se pedía (Montero, n.d.; Sauquillo, 16-11-2012); menos favorable suele ser el balance que hacen en el terreno político, por la distancia entre el proyecto político que defendían y el régimen político que se consolidó en el país (Quiñonero, 23-03-2012). 


\section{Conclusiones: protagonistas de la Transición "desde abajo"}

Se han propuesto numerosos factores que pueden explicar la crisis en que se sumieron estos partidos desde finales de los años setenta, que condujo a la desorientación y abandono de destacados sectores de la militancia, fuertes tensiones internas, escisiones e incluso la desaparición del PTE y la ORT. Algunos de ellos fueron comunes, como la aparición de nuevas formas de canalizar las demandas sociales, la desmovilización una vez que se consiguió la prioridad de acabar con la dictadura, el desencanto de las bases sociales ante la imposibilidad de alcanzar el horizonte político socialista o de profundización de la democracia y los decepcionantes resultados electorales, que no respondieron al esfuerzo realizado en los años anteriores. Además, en el caso del PCE, se apunta el cambio en la estrategia del partido para adaptarse a la democracia representativa simbolizado en la renuncia al leninismo y las apelaciones al eurocomunismo, y el paso de la movilización social a la vía institucional (Molinero e Ysàs, 2008 y Andrade Blanco, 2012). Para la extrema izquierda, se alude al lastre de unas formas de organización ajustadas a la clandestinidad, que fue difícil adaptar al contexto de ampliación de libertades, la pérdida de referentes internacionales ante el pragmatismo de la China maoísta o el enfrentamiento entre Vietnam y Camboya, la desorientación ideológica y el desgaste de una militancia con un alto grado de compromiso político (Sans Molas, 2011: 658-665).

Sin embargo, aunque los resultados electorales de 1977 y 1979 no reflejaron la entrega y la labor arriesgada de los y las militantes del universo comunista, dicha acción fue fundamental en el cambio político que experimentó España no tanto en los despachos sino en la calle, una experiencia poco conocida por la centralidad que muchas veces se concede a la ruptura pactada y a la labor de los partidos mayoritarios e instituciones como la corona o el Parlamento (Rodríguez Tejada, 2011: 631). Desde hace tiempo se ha apuntado una interpretación de la Transición que concede una gran relevancia a la movilización social, que presionó y consiguió implantar la democracia; al mismo tiempo se indica que los movimientos sociales se convirtieron en espacios de aprendizaje de prácticas democráticas, tareas en que fue esencial la actuación de la militancia del PCE (Molinero, 2010: 283). También se ha señalado que la principal aportación de los grupos políticos de la extrema izquierda fue la generosidad y abnegación de sus integrantes (Errejón, 2011: 80).

En este sentido, las militantes del heterogénero universo comunista introdujeron en sus culturas políticas los discursos igualitarios, reformularon las identidades masculinas y femeninas de la izquierda, contribuyeron de forma poderosa a que el feminismo modificara la agenda política de los grandes partidos, incorporaron a numerosas mujeres a la movilización antifranquista y feminista, difundieron nuevos valores de justicia e igualdad, y aunque no alcanzaron el socialismo, ensancharon los límites de la cultura democrática en nuestro país. 


\section{Bibliografía}

- Abad Buil, Irene (2005): "Movimiento Democrático de Mujeres. Un vehículo para la búsqueda de una nueva ciudadanía femenina en la transición española”. En: Actes del Congrés La Transició de la dictadura franquista a la democracia. Barcelona: Universitat Autònoma de Barcelona, pp. 245-252.

. (2012): En las puertas de prisión. De la solidaridad a la concienciación política de las mujeres de los presos del franquismo. Barcelona: Icaria.

- Aguado, Ana (2010): “Cultura socialista, ciudadanía y feminismo en la España de los años veinte y treinta”. En: Historia Social, n 67, pp. 131-153.

- Aguado, Ana y Ortega, Teresa Ma (2011) (eds.): Feminismos y antifeminismos. Culturas políticas e identidades de género en la España del siglo XX. Valencia: Universitat de València.

- Andrade Blanco, Juan Antonio (2012): El PCE y e PSOE en (la) transición. La evolución ideológica de la izquierda durante el proceso de cambio político. Madrid: Siglo XXI.

- Augustín Puerta, Mercedes (2003): Feminismo: identidad personal y lucha colectiva. Análisis del movimiento feminista español en los años 1975 a 1985. Granada: Universidad de Granada.

- Calamai, Natalia (1977): "Hacia la liberación de la mujer". En: Nuestra Bandera, julioagosto, no $88-89$, pp. 40-45.

- Calamai, Natalia (1978): “¿Trabajo ‘femenino’ o trabajo ‘feminista’?”. En: Mundo Obrero, 2 al 8 de febrero, $n^{\circ} 5$, p. 15.

- Calamai, Natalia y Lozano, Marian (1978a): “La política 'feminista' de UCD”. En: Mundo Obrero, 12 a 18 de octubre, $\mathrm{n}^{\circ} 43$, p. 14.

- Calvet, Dolors (1979): “Jornadas feministas. No hubo aportaciones nuevas”. En: Mundo Obrero, 20 al 26 de diciembre, $n^{\circ}$ 54, pp. 20-22.

- Combate (1976): "Radiografía de la LCR", 1ª quincena de septiembre, nº 57, pp. 10.

- Cruz, Rafael (1999): Pasionaria. Dolores Ibárruri, historia y símbolo. Madrid: Biblioteca Nueva.

- Cucó i Giner, Josepa (2008): "Recuperando una memoria en la penumbra: el Movimiento Comunista y las transformaciones de la extrema izquierda española". En: Historia y Política. Ideas, procesos y movimientos sociales, $\mathrm{n}^{\circ}$ 20, pp. 73-96.

- Díaz Alcaraz, Silvia [Entrevista], Alicante, 13-06-2006.

- Domènech Sampere, Xavier (2010): “Cenizas que ardían todavía. La identidad comunista en el tardofranquismo y la transición”. En: Manuel Bueno Lluch y Sergio Gálvez Biesca (eds.): Nosotros, los comunistas. Memoria, identidad e historia social. Madrid: FIM, pp. 93-138.

- Erice Sebares, Francisco (1996): "Mujeres comunistas. La militancia femenina en el comunismo asturiano, de los orígenes al final del franquismo". En: Francisco Erice Sebares (coord.): Los comunistas en Asturias (1920-1982). Gijón: Trea, pp. 313-344. 
(2010): "El 'orgullo de ser comunista'. Imagen autopercepción, memoria e identidad colectiva de los comunistas españoles”. En: Manuel Bueno Lluch y Sergio Gálvez Biesca (eds.): Nosotros, los comunistas. Memoria, identidad e historia social. Madrid: FIM, pp. 139183.

- Errejón, Juan Antonio (2011): “El Partido del Trabajo de España”. En: Viento Sur, n 115, pp. 79-86.

- Escudero Andújar, Fuensanta y González Martínez, Carmen (2011): “Jóvenes y rebeldes: el idealismo efimero de la extrema izquierda". En: V Congreso Internacional Historia de la Transición en España. Las organizaciones políticas, Almería, pp. 507-534.

- Iribarren, Sara (1975): “Acerca de la militancia femenina”. En: Mundo Obrero, 10 de noviembre, $\mathrm{n}^{\mathrm{o}} 36, \mathrm{p}$. VI).

- Laiz, Consuelo (1995): La lucha final. Los partidos de la izquierda radical durante la transición española. Madrid: La Catarata.

- LCR (n.d. a): Primera Conferencia sobre la Mujer. Madrid. . (n.d. b): Ley de divorcio que no discrimine a las mujeres. Madrid.

(1978): Una Constitución al servicio del gran capital. Madrid.

- MC (1978): La lucha de la liberación de la mujer. Resolución del II Congreso del MC. Serie Liberación de la Mujer, Madrid.

- MC-OIC (1978): Hacia la unidad. Documentos para la preparación del Congreso Extraordinario de unificación. Madrid.

- MCPV-OEC (1979): Proposición de ley de defensa y protección del aborto.

- Molinero, Carme (2010): "Una gran apuesta: la oposición política a través de la movilización social”. En: Manuel Bueno Lluch y Sergio Gálvez Biesca (eds.): Nosotros, los comunistas. Memoria, identidad e historia social. Madrid: FIM, pp. 255-283.

- Molinero, Carme e Ysàs, Pere (2008): "La izquierda en los años setenta". En: Historia y Política. Ideas, procesos y movimientos sociales, $\mathrm{n}^{\circ} 20,21-42$.

- Montero, Justa [Entrevista], Madrid, n.d., Seminario de Fuentes Orales, [en línea] Disponible en http://www.seminariofuentesorales.es/ [26-02-2013].

- Moreno Seco, Mónica (2008): "Mujer y culturas políticas en el franquismo y el antifranquismo". En: Pasado y Memoria. Revista de Historia Contemporánea, $\mathrm{n}^{\circ}$ 7, pp. 165185 .

(en prensa a): “A la sombra de Pasionaria. Mujeres y militancia feminista (19601982)”. En: María Dolores Ramos (coord.): Tejedoras de ciudadanía. Culturas políticas, feminismo y acción colectiva. Málaga: Universidad de Málaga.

(en prensa b): “Compromiso y género en la extrema izquierda española de los años setenta”. En: Karine Bergès (ed.), Engagées. Activisme politique des femmes aux XXe et XXIe siècles. Rennes: Presses Universitaires de Rennes.

- Mundo Obrero (1975): “¡El partido de la liberación de la mujer!”, 4 semana de septiembre, $\mathrm{n}^{\circ} 29$, p. 8.

- Mundo Obrero (1975):"El manifiesto del Partido por la liberación de la mujer", $3^{\text {a }}$ semana de octubre, $\mathrm{n}^{\mathrm{o}} 32$, p. VII. 
- Mundo Obrero (1976): "Propuesta de programa", 29 de septiembre, n 34, pp. 9-11.

- Mundo Obrero (1977): "Los comunistas y su por qué”, 10 de abril, no 15, p. 8.

- Mundo Obrero (1977): “Amnistía también para la mujer”, 3 de agosto, no 31, p. 4.

- Mundo Obrero (1978): "El feminismo y el partido", 20 de abril, no 16, p. 6.

- Mundo Obrero (1978): "Proyecto de ley del divorcio", 18 al 24 de junio, n 21, p. 4.

- Mundo Obrero (1980): "Proposición de ley comunista. La realidad del aborto", 22 a 28 de mayo, $\mathrm{n}^{\mathrm{o}} 76$, pp. 22-23.

- Mundo Obrero (1981): "Tesis aprobadas por el X Congreso del PCE”, 16 a 22 de octubre, no 147 , pp. 14-15.

- Nash, Mary (2009): "Mujeres en transición: ciudadanía femenina, legitimidad feminista y la creación de una nueva cultura política”. En: Mary Nash y Gemma Torres (eds.): Feminismos en la Transición. Barcelona: Grup de Recerca Consolidat Multiculturalismo i Gènere, Universitat de Barcelona, Sociedad Estatal de Conmemoraciones Culturales, pp. 71-88.

(2011): "La construcción de una cultura política desde la legitimidad feminista durante la Transición política democrática”. En: Ana Aguado y Teresa M ${ }^{\mathrm{a}}$ Ortega (eds.): Feminismos y antifeminismos. Culturas políticas e identidades de género en la España del siglo XX. Valencia: Universitat de València, pp. 283-306.

- Nuestra Bandera (1978): "La liberación de la mujer", mayo-junio, no 93, pp. 71-77.

- Nuestra Bandera (1979): “Conferencia del PCE sobre la mujer”, enero, nº 97, pp. 33-38.

- Pardo Buendía, Mercedes (1978): "Puntualización sobre las I Jornadas de la Condición Femenina". En: Mundo Obrero, 9 al 15 de noviembre, n 47, p. 14.

- PCE (1976): Hacia la liberación de la mujer. I Conferencia del PCE sobre la condición femenina, Madrid.

- Pérez Ledesma, Manuel (2006): “'Nuevos' y 'viejos' movimientos sociales en la Transición”. En: Carme Molinero (ed.): La Transición, treinta años después. De la dictadura a la instauración y consolidación de la democracia. Barcelona: Península, pp. 121-152.

- Pineda, Empar (1984): "El feminismo y las instituciones”. En: Servir al Pueblo, 9 al 22 de marzo, no 223, p. 15.

- Quiñonero, Llum [Entrevista], Alicante, 23-III-2012.

- Radcliff, Pamela Beth (2009): "La historia oculta y las razones de una ausencia. La integración del feminismo en las historiografías de la transición”. En: Carmen Martínez Ten, Purificación Gutiérrez López y Pilar González Ruiz (eds.): El movimiento feminista en los años 70. Madrid: Fundación Pablo Iglesias-Cátedra, pp. 53-70.

- Reig Cruañes, Cita [Entrevista], Alicante, 15-06-2006.

- Roca, José Manuel (1993): "La izquierda comunista revolucionaria en España (19641992)". En: Leviatán, no 51-52, pp. 89-117.

- Rodríguez Tejada, Sergio (2011): "Nueva izquierda, extrema izquierda: bases intelectuales y prácticas militantes de las organizaciones revolucionarias al inicio de la Transición española”. En: V Congreso Internacional Historia de la Transición en España. Las organizaciones políticas. Almería, pp. 631-648. 
- Rubial, Amparo (1979): "Los comunistas jugamos un papel muy importante". En: Mundo Obrero, 27 de enero, $\mathrm{n}^{\circ} 59, \mathrm{p} .4$.

- Ruiz, Fernando y Romero, Joaquín (1977) (eds.): Los partidos marxistas. Sus dirigentes, sus programas. Barcelona: Anagrama.

- Sánchez Jiménez, Jesús (2004): “Teoría y práctica democrática en el PCE, 1956-1982". En: Utopías. Nuestra Bandera, $\mathrm{n}^{\circ} 200$ dedicado al I Congreso sobre la Historia del PCE, pp. 81-93.

- Sanjuán Ayelo, Rosalía [Entrevista], Villena, 01-02-2013.

- Sans Molas, Joel (2011): "Entre las instituciones y la movilización: la crisis de la izquierda radical durante la Transición". En: V Congreso Internacional Historia de la Transición en España. Almería, pp. 649-665.

- Sauquillo, Francisca [Entrevista], Madrid, 16-11-2012.

- Sender Begué, Rosalía (2004): Nos quitaron la miel. Memorias de una luchadora antifranquista. Valencia: Universitat de València.

. (2006): Luchando por la liberación de la mujer. Valencia, 1969-1981. Valencia: Universitat de València.

- Servir al Pueblo (1978): "Estructura autónoma de mujeres", $2^{\mathrm{a}}$ quincena de abril, no 100, p. 19.

- Uría Ríos, Paloma (2009): El feminismo que no llegó al poder. Trayectoria de un feminismo crítico. Madrid: Talasa.

- Verdugo Martí, Vicenta (2011): "Prácticas políticas y movimiento feminista en el País Valenciano (1976-1982)". En: Ana Aguado y Teresa Ma Ortega (eds.): Feminismos y antifeminismos. Culturas políticas e identidades de género en la España del siglo XX. Valencia: Universitat de València, pp. 333-358.

- Viento del Pueblo (1975): "Movimiento feminista", julio, p. 5

- Yzaguirre, Pilar de (1979): "La mujer frente a las elecciones: análisis comparado de las listas electorales”. En: El País, 11 de febrero, p. 21. 